\title{
Ozone aeration impact on the maturation phase in the process of green waste composting
}

\author{
Maciej Gliniak ${ }^{1} *$, Lukasz Grabowski², Daria Polek $^{2}$ \\ ${ }^{1}$ University of Agriculture in Krakow, Institute of Agriculture Engineering and Informatics, Faculty of Production and Power \\ Engineering, Mickiewicza 21 Av., 30-120 Krakow, Poland \\ ${ }^{2}$ AGH University of Science and Technology, Faculty of Mining and Geoengineering, Department of Environmental Engineering \\ and Mineral Processing, Mickiewicza 30 Av., 30-059 Krakow, Poland
}

\begin{abstract}
The paper presents work results on optimization of stabilization phase in the biomass composting process. In these studies, it was examined the influence of two doses of ozone (10 and $20 \mathrm{mgO}_{3} \cdot \mathrm{dm}^{-3}$ ) in the air used for aeration of stabilization. The results showed the ability to reduce compost maturation time by more than $50 \%$. Application of these ozone doses resulted in a reduction of organic matter content in the stabilizer by 30 to $60 \%$, while reduction of moisture in the material by $20 \%$.
\end{abstract}

\section{Introduction}

Intensive socio-economic development observed in Poland in recent years, resulted in a significant increase of biodegradable waste volume. In accordance with applicable law and the EU concept called circular economy, one should strive to make the best use of raw materials obtained in the process of waste recovery and recycling. In Poland, the material recovery has been regulated at Regulation of the Minister of the Environment from 2015 on the recovery process R10, in the provisions of the Waste Act of December 2012 and in guidelines of the Department of Waste Management in the Ministry of Environment from December 2008. After analysis of these documents, it was found that the main process of recovering raw materials from biomass is the composting process [1-6].

In the moderate climate conditions, the composting process is divided into two phases, which both should not take less than 8 weeks [2-4]. The duration of the process depends on the choice of composting methods (active system with aeration of the material or passive without aeration) and the material properties which is going to be processed. Beside these factors the impact on composting process have also $\mathrm{pH}$, ambient air temperature, amount of microorganisms, components containing auxiliary source of carbon [7]. Based on the studies carried out in different research centres, it was found that the first phase of the composting process should last about 2 weeks. Then the material is directed for the stabilization, which takes 6-8 weeks $[2-4,8]$, the obtained compost must meet the following criteria [2]:

a) loss of ignition (LOI) - below $35 \%$ of the dry mass,

b)total organic carbon (TOC) - less than $20 \%$,

c)AT4 respiration activity - not exceeding 10 $\mathrm{mgO}_{3} \cdot \mathrm{g}^{-1}$ of dry mass.
In establishments, which carry out composting waste, there is a need to comply with quality standards, which often forces to extend the process length. It also affects the decline in their production capacity. Currently in the world there are many researches over the optimization of the composting process kinetics in its first phase and elimination of associated odorous emissions [8-14]. Optimization of stabilization phase in the composting process is mainly focused on the use of various substances for neutralizing additional contaminants (eg. toxic metals, petroleum products, etc.). In addition, in the literature there are several studies that suggest an additional hygienization of stabilized material and the possibilities of using gases generated in the process [15$20]$.

Literature review showed that the main problem of the composting process is a lenght of its stabilization phase. Previous studies conducted in the world related to the use of ozone in the composting process, were focused on the disposal of leachate $[21,22]$. Due to the lacks in research and data in the literature, which regards to possibilities of shortening phase of aerobic stabilization, it was decided to investigate whether it is possible to use ozone as a substance, which affects both the additional hygienization of the material and acceleration of stabilization in composting process.

\section{Material and Methods}

The composting process was carried out in the isothermal bioreactor BKB 100 used for testing of digestibility of organic material. Based on previous laboratory tests it was found that the course of the decomposition of organic matter in the bioreactor is similar to the actual conditions occurring in the

\footnotetext{
Corresponding author: maciej.gliniak@urk.edu.pl
} 
composting containers [1,23,24]. The study used the mixture of biomass consisting: grass $(50 \%)$, sawdust $(25 \%)$ and food waste $(25 \%)$ - in the total fresh weight of $30 \mathrm{~kg}$. The composition of the mixture was selected to obtain the appropriate structural properties of compost, while ensuring: a proper flow of air in the bioreactor, the humidity of mixed biomass used for the process was $63 \%$ and the $\mathrm{C}: \mathrm{N}$ ratio was 23.8 . In order to obtain the proper process of composting and trigger clear thermophilic phase, one set air flow in the bioreactor at a level of $0.035 \mathrm{~m}^{3} \cdot \mathrm{h}^{-1} \cdot \mathrm{kg}_{\mathrm{dw}}{ }^{-1}$ (which based on the weight of the composted waste was about $0.4 \mathrm{~m}^{3} \cdot \mathrm{h}^{-1}$ ). In a study conducted by Dziedzic et al. [25] and Malinowski and Wolny-Koladka [26], it was demonstrated that such flow provides adequate aeration of biomass $\left(>10 \% \mathrm{O}_{2}\right.$ content) and does not lead to supercooling of material.

As soon as thermophilic phase of composting process has been completed (material reached the temperature of $45^{\circ} \mathrm{C}$ after the passage on the inflection point which defines the maximum temperature of the process) one collected three representative samples of the material from the bioreactor with a mass of $1500 \mathrm{~g}$ for the air stabilization process with ozone content of 0,10 and 20 $\mathrm{mgO}_{3} \cdot \mathrm{dm}^{-3}$. Each representative sample was then divided into three equal parts weighing $500 \mathrm{~g}$ each, for a total of three sets of samples for the ozone aeration. To produce air containing ozone used ozone generator O3PRO DRP30,7VW by Prozonex (Poland). The stabilization was carried out in round-bottom flasks having a volume of $500 \mathrm{ml}$, equipped with the air diffuser at the bottom of the flask, fitted with a sensor PT-1000 for measuring the temperature connected to a recording computer. During aeration, flasks were assembled in a laboratory shaker type LP-Shaker360 (simulation of compost flipping on a pile). Aeration process of the samples took 28 days (achieved ambient stabilization temperature), and was divided into seven four-day cycles:

- day 1: measuring the initial temperature and shaking the sample with ozone aeration for 5 minutes,

- day 2: break,

- day 3: measuring the initial temperature and shaking the sample for 5 minutes,

- day 4: break.

After the end of the stabilization process, obtained compost was sieved through a sieve with an aperture of 2 $\mathrm{mm}$ and analyzed in terms of moisture content using the gravimetric method according to ISO 11465:1999 and the loss on ignition according to EN 15169:2011. After stabilization process, from each sample was collected 40 $\mathrm{g}$ of material in 2 replicates to determine the aerobic activity of the material according to the Richtlinie für die mechanisch-biologische Behandlung von Abfällen.

\section{Results}

Due to the fact that the thermophilic microorganisms are the most active at temperatures above $45^{\circ} \mathrm{C}$, such value was adopted as the lower boundary for thermophilic phase of the composting process in the experiment and the beginning of the compost stabilization process [3,9]. As a point of achieving thermal stability of the composted material one assigned the ambient temperature which was equal to $23^{\circ} \mathrm{C}$ maintained for a minimum 2 consecutive nights. Thermal stabilization of blank test was reached after 26 days from the start of measurement procedure (Fig. 1a). Samples aerated with air containing $10 \mathrm{mgO}_{3} \cdot \mathrm{dm}^{-3}$ resulted in shorter stabilization time for 10 days $(40 \%$ of the standard stabilization time) compared to blank sample (Fig. 1b). Air applied for stabilization with the content of 20 $\mathrm{mgO}_{3} \cdot \mathrm{dm}^{-3}$ (Fig. 1c) effected in compost thermal stability after 12 days of stabilization ( $54 \%$ to $40 \%$ of the standard stabilization time). While analyzing the curves shown in Fig. 1 there is an increase in slope of the temperature with increasing concentration of ozone. The presence of this relationship may indicate faster hygienization of obtained stabilizer, so the decline of thermophilic microorganisms in the sample.
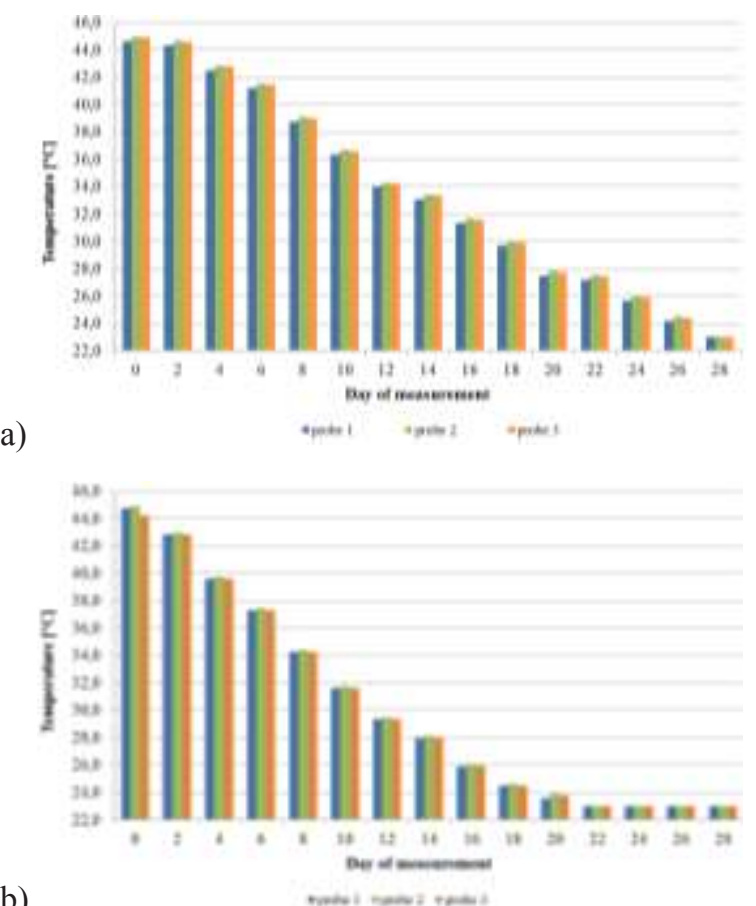

b)

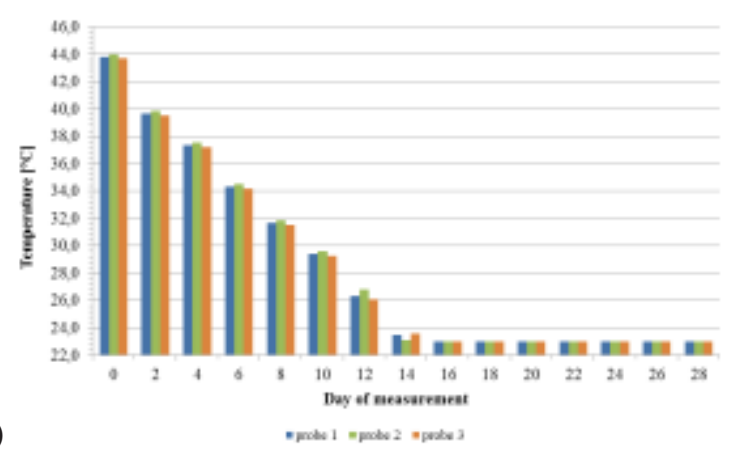

Fig. 1. Changes of temperature in stabilization phase of the composting process depending on the concentration of ozone in the air: (a) the blank, (b) air containing 10 $\mathrm{mgO}_{3} \cdot \mathrm{dm}^{-3}$, (c) air containing $20 \mathrm{mgO}_{3} \cdot \mathrm{dm}^{-3}$ [author's work]

Relevance analysis of the results obtained for each sample was performed based on Pearson's linear correlation $(n=9)$, using a significance level of $\mathrm{p}=0.05$. 
Pearson coefficient used for concentrations of ozone in the air used for the stabilization of the samples reached the highest value for the blank test (0.99). Samples aerated with ozone also reached higher degree of correlation of $0.92\left(10 \mathrm{mgO}_{3} \cdot \mathrm{dm}^{-3}\right)$ and $0.81 \quad(20$ $\mathrm{mgO}_{3} \cdot \mathrm{dm}^{-3}$ ). In all analyzed cases, the correlation had strongly positive nature. Analysis of standard deviations from medium temperature for ozonized samples (Fig. 2) showed variability in the range of $0.12 \div 0.14^{\circ} \mathrm{C}$.

By monitoring the average changes in temperature of the samples aerated without the ozone addition, one can observe the presence of 3 stabilizing points after the material temperature reached 45,34 and $28^{\circ} \mathrm{C}$. Samples aerated with $10 \mathrm{mgO}_{3} \cdot \mathrm{dm}^{-3}$ also showed the presence of stabilization points, but the temperature was reduced by about $2.5^{\circ} \mathrm{C}$ in relation to the blank. The analysis of the average temperature for samples aerated with 20 $\mathrm{mgO}_{3} \cdot \mathrm{dm}^{-3}$ (Fig. 2) showed the disappearance of the stabilization points, which can be explained by reaching toxic concentrations of ozone in the air used for the analysis for micro-organisms present in the stabilization process.

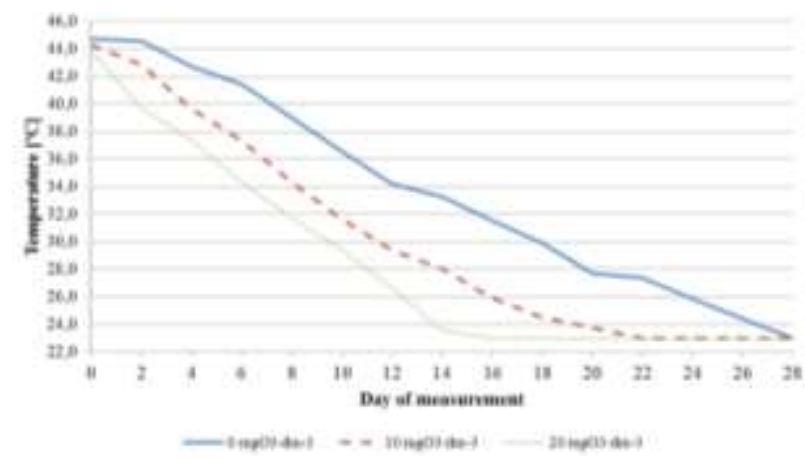

Fig. 2. Variability of average temperature in the stabilization phase of the composting process depending on the concentration of ozone in the air [author's work]

The use of ozone in the stabilization process of the samples did not affect the content of unprocessed biomass in the resulting compost, sifted through a sieve with an aperture of $2 \mathrm{~mm}$. Analysis of the quality parameters of obtained compost indicates the existence of relationship between the amount of ozone applied to the stabilization and its moisture and organic matter content (expressed as loss on ignition). The use of air containing ozone at $20 \mathrm{mgO}_{3} \cdot \mathrm{dm}^{-3}$ resulted in the loss of moisture content of $8 \%$ and a decrease in organic matter content of $58 \%$ compared to the blank.

The experiment proved a positive ozone influence on accelerating the stabilization phase in the composting process. The proposed solution may be a contribution in the ongoing work on the intensification of thermophilic phase during processing of biomass. Analysis of the results showed that the increase in the concentration of ozone in the air deployed to stabilize the compost results in proportional decrease of its duration. In both analyzed cases (addition of $10 \mathrm{mgO}_{3} \cdot \mathrm{dm}^{-3}$ and $20 \mathrm{mgO}_{3} \cdot \mathrm{dm}^{-3}$ ) one showed a decrease in moisture content from $32 \%$ to about $26 \%$, and organic matter content of the product from $26 \%$ to respectively $19 \%$ and $11 \%$ in comparison to the sample aerated without the use of ozone. $\mathrm{pH}$ of obtained compost did not depend on ozone concentration in the air and was at the level of 6.1. Oxygen activity of obtained compost was $10.01,8.56$ and $8.17 \mathrm{mgO}_{2} \cdot \mathrm{g}_{\mathrm{dw}}{ }^{-1}$ (for respectively aeration $0,10,20 \mathrm{mgO}_{3} \cdot \mathrm{dm}^{-3}$ ).

\section{References}

1. K. Grzesik, M. Malinowski, Energy Sources, Part A: Recovery, Utilization, and Environmental Effects, 38, 21, 3150-3157 (2016)

2. Guidelines of the Department of Waste Management in the Ministry of Environment in Poland from December 2008, pp 35.

3. Waste Act in Poland from December 2012 (Dz. U. 2013 poz. 21).

4. P. Ghisellini, C. Cialani, S. Ulgiati, Journal of Cleaner Production, 114, 11-32 (2016)

5. A.B. Morales, M.A Bustamante, F.C. MarhuendaEgea, R. Moral, M. Ros, J.A. Pascual, Journal of Cleaner Production, 121, 186-197 (2016)

6. M. Mourad, Journal of Cleaner Production, 126, 461477 (2016)

7. A.D. Neklyudov, G.N. Fedotov, A.N. Ivankin, Applied Biochemistry and Microbiology, 44, 1, 9-23 (2008)

8. R. Lebrero, E. Rodríguez, P.A. García-Encina, R. Muñoz, Journal of Hazardous Materials, 190, 1-3, 622-630 (2011)

9. M.C. Gutierez, M.A. Martin, A. Serrano, A.F. Chica, Journal of Environmental Management, 151, 531539 (2015)

10. J. Yuan, Q. Yang, Z. Zhang, G. Li, W. Luo, D. Zhang, Journal of Environmental Sciences, 37, 83-90 (2015)

11. C. Fernández, C. Mateu, R. Moral, F. Sole-Mauri, Environmental Modelling \& Software, 79, 156-166 (2016)

12. G. Jinyi, H. Guangqun, H. Jing, Z. Jianfei, H. Lujia, International Journal of Heat and Mass Transfer, 97, 735-741 (2016)

13. J.A. Siles, F. Vargas, M.C. Gutiérrez, A.F. Chica, M.A. Martín, Bioresource Technology, 211, 173-182 (2016)

14. W. Yongjiang, P. Li, L. Xinyu, W. Yuansheng, Z. Kexun, L. Fei, Bioresource Technology, 206,164-172 (2016)

15. F. Benlboukht, L. Lemee, S. Amir, A. Ambles, M. Hafidi, Ecological Engineering, 90, 87-95 (2016)

16. Z. Junya, Ch. Meixue, S. Qianwen, T. Juan, J. Chao, L. Xueting, Z. Yuxiu, W. Yuansong, Water Research, 91, 339-349 (2016)

17. Y. Lian, Z. Shihua, Ch. Zhigiang, W. Qinxue, W. Yao, Bioresource Technology, 204, 185-191 (2016) 
18. K.A. Mukesh, K.P. Akhilesh, S.B. Pushpendra, W.C. Wong, R. Li, Z. Zengqiang, Bioresource Technology, 213, 181-189 (2016)

19. B. Vandecasteele, T. Sinicco, T. D'Hose, N.T. Vanden, C. Mondini, Journal of Environmental Management, 168, 200-209 (2016)

20. W. Yuquan, W. Zimin, C. Zhenyu, Z. Yue, Z. Xinyu, L. Qian, W. Xueqin, Z. Xu, Bioresource Technology, 211, 610-617 (2016)

21. N. Mokhtarani, A. Nasiri, H. Ganjidoust, S.Y. Yasrobi, The Journal of the International Ozone Association, 36, 6, 540-548 (2014)

22. M.M. Amin, M.A. Moazzam, International Journal of Environmental Health Engineering, 3, 1, 24-29 (2014)

23. S. Kasiński, I. Wojnowska-Baryla, Compost Science \& Utilization, 21, 3-4, 147-155 (2013)

24. M. Hurka, M. Malinowski, Infrastructure and ecology of rural areas, 4, 1, 1127-1136 (2014)

25. K. Dziedzic, B. Łapczyńska-Kordon, M. Malinowski, M. Niemiec, J. Sikora, Chemical and Process Engineering, 36, 4, 381-394 (2015)

26. M. Malinowski, K. Wolny-Koładka, Proceedings of ECOpole, 9, 1, 256-261 (2015) 